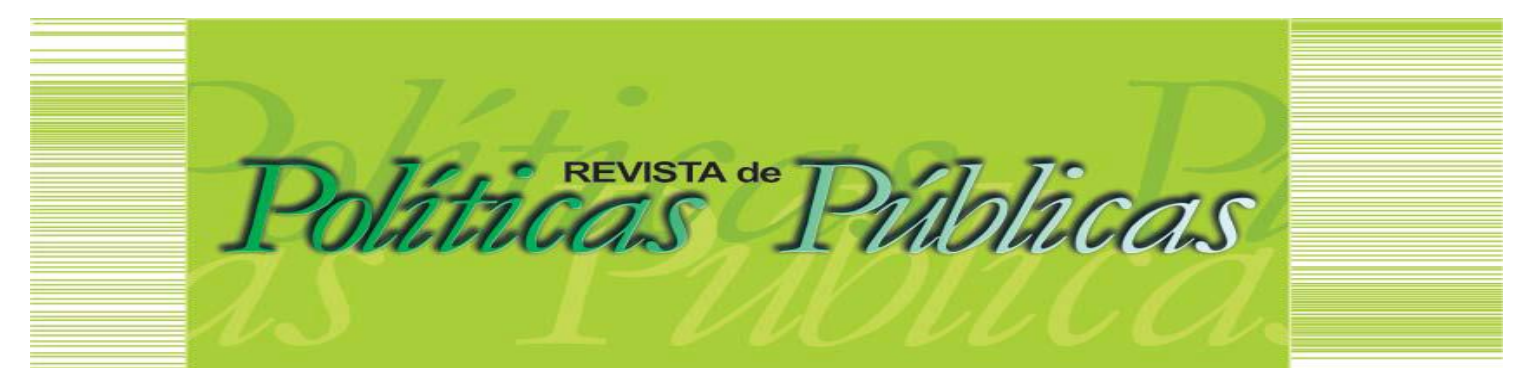

\title{
O FRACASSO DAS PRÁTICAS ESTATAIS COMO SUA JUSTIFICATIVA: Projetos de
}

\author{
Policiais-Professores na Cidade de Deus
}

Luana Dias Motta ${ }^{1}$

\begin{abstract}
Resumo:
Este texto problematiza os esforços estatais de conter o conflito contemporâneo nas margens urbanas, a partir de um caso empírico: projetos conduzidos por policiais militares cedidos pela Unidade de Polícia Pacificadora da Cidade de Deus. A partir de etnografia que acompanhou a rotina desses policiais-professores e em diálogo com uma perspectiva desessencializada do Estado, argumento que as explicações para os problemas das favelas estão assentadas no que seriam as características da comunidade. Essas características explicariam a manutenção dos problemas sociais e da violência, a despeito dos projetos. Nessa narrativa, muito comum nas políticas para pobres, oblitera-se uma reflexão sobre a concepção e a implementação da política. A ineficácia dos projetos emerge como um indicador de quão difícil é, à comunidade, fazer do fracasso a justificativa para a manutenção dessas mesmas políticas.
\end{abstract}

Palavras-chave: Projetos sociais. Policiais militares. Conflito urbano. Pobreza. Violência.

THE FAILURE OF THE STATE ACTIONS AS ITS JUSTIFICATION: police-teachers' projects in the cidade de deus slum

\section{Abstract:}

This paper discusses the state efforts to manage and contain the contemporary conflict on the urban margins from a empirical case: projects conducted by military police officers assigned by the Pacifying Police Unit in the Cidade de Deus slum. From an ethnography of the routine of these state agents and in dialogue with a desessential perspective of the State, I argue that the explanations for the problems of slums are based on the characteristics of the community. These characteristics would explain the maintenance of social problems and the problem of violence. In this narrative, very common for poor people, a reflection on the conception and the implementation of the politics itself is obliterated. The ineffectiveness of projects in transforming reality emerges as an indicator of how difficult the community is, turning the very failure into justification for the need to maintain those same policies.

Keywords: Social projects. Military police officers. Urban conflict. Poverty. Violence.

Artigo recebido em: 21/01/2019 Aprovado em: 04/04/2019. DOI: http://dx.doi.org/10.18764/2178-2865.v23n1p171-190

\footnotetext{
1 Graduada em Ciências Sociais. Doutora em Sociologia pela Universidade Federal de São Carlos (UFSCar). Professora Adjunta do Departamento de Sociologia da UFSCar. Endereço: Rodovia Washington Luiz, 235. São Carlos. São Paulo. Email: luanadmotta@yahoo.com.br
} 


\section{INTRODUÇÃO}

A literatura sobre as periferias urbanas argumenta que, nas últimas três décadas, o conflito urbano teve seu cerne radicalmente deslocado do problema da integração das classes trabalhadoras das periferias urbanas para a questão da violência que emanaria desses espaços (FELTRAN, 2011; 2014a; MACHADO DA SILVA, 2010; 2011; MISSE, 1993). A violência passa a figurar como cerne do problema da pobreza urbana; o conflito social se traduz em conflito criminal. Tal deslocamento tem implicado uma radicalização da alteridade, na medida em que a pobreza e os pobres passam a ser entendidos e representados como sinônimo de marginalidade, criminalidade e fonte da violência. (FELTRAN, 2014b).

Este texto ${ }^{1}$ problematiza os esforços estatais de gerir e conter o conflito urbano contemporâneo nas margens urbanas, tendo como ponto de partida um caso empírico específico: os projetos $^{2}$ conduzidos por policiais militares cedidos pela Unidade de Polícia Pacificadora (UPP) da Cidade de Deus, os quais acompanhei em pesquisa etnográfica. Seguindo a rotina desses policiaisprofessores ${ }^{3}$ no Prédio do Centro de Referência da Juventude (CRJ) da Cidade de Deus - ao longo de 4 meses em 2014, quando residi nessa favela, e em incursões de campo ao longo do ano de 2016 -, pude acompanhar suas atividades, os problemas que enfrentavam, os dilemas que viviam, as reflexões que construíam acerca dos problemas das favelas e sua suposta relação com a violência urbana e de como poderiam incidir sobre isso.

O valor heurístico do caso dos policiais-professores da Cidade de Deus para refletir sobre os esforços estatais de contenção do conflito urbano no Brasil está relacionado a três dimensões principais: i) o fato de esses projetos terem sido conduzidos no contexto de implementação de uma nova política de segurança pública, as Unidades de Polícia Pacificadora, que se apresentava como alternativa inovadora para conter a violência que emanaria das favelas; ii) o fato de a questão da contenção, combate e prevenção à violência ser o foco principal e último das práticas desses policiaisprofessores, que afirmavam combinar segurança e social para lidar com o problema da violência de modo mais efetivo; iii) o fato de olharmos para a ponta, para os modos como a política é implementada e recebida pelo público-alvo, ou seja, por podemos ver o Estado se fazendo em ato.

0 interesse pelos esforços estatais de gestão do conflito urbano está, portanto, no nível das práticas ordinárias, rotineiras e cotidianas de agentes que implementam políticas, que estão na ponta; aqueles que Lipsky (1980) chamou de burocratas de nível de rua. Ou seja, parto de uma perspectiva que entende o Estado não com uma espécie de dado histórico-natural (FOUCAULT, 2000; 2008), mas, ao contrário, busco entendê-lo e estudá-lo na imanência: práticas, relações, documentos, normativas, funcionamentos, pessoas, espaços concretos etc., sem procurar algo transcendente 
O FRACASSO DAS PRÁTICAS ESTATAIS COMO SUA JUSTIFICATIVA: Projetos de Policiais-Professores na Cidade de Deus

(FOUCAULT, 2000, 2008). Nesse sentido, as ações dos agentes estatais não são tomadas apenas como "[...] produto de um Estado já pronto. As ações feitas em nome do Estado [...] constroem o próprio Estado." (SOUZA LIMA, 2002, p. 54). Em outras palavras, o Estado aqui é tomado como uma realidade concreta e situada, não uma abstração ou entidade neutra. (FASSIN, 2013). Vale destacar que isso não significa obliterar o efeito Estado (MITCHELL, 1999), mas reconhecer que a força da ideia do Estado como um conjunto de estruturas reificadas e desencarnadas é um efeito das próprias práticas do Estado.

É nesse sentido que Veena Das e Deborah Poole (2004) propõe uma reflexão sobre o Estado a partir de suas manifestações, figurações e presenças concretas. A proposta analítica é distanciar-se "[...] da imagem consolidada do Estado como forma administrativa de organização política racionalizada que tende a debilitar-se ou desarticular-se ao longo de suas margens territoriais e sociais." (DAS; POOLE, 2004, p. 19) para, assim, refletir "[...] como as práticas e políticas de vida nas margens moldam as práticas políticas de regulação e disciplinamento que constituem aquilo que chamamos 'o Estado" (DAS; POOLE, 2004, p. 22). Nessa perspectiva, Das e Poole (2004) advertem que olhar para o Estado a partir de suas margens significa abster-se da ideia de que práticas de agentes estatais nesses espaços e junto a essas populações seriam falhas, uma disfunção, algo externo ao Estado ou uma exceção. Ao contrário, o pressuposto das autoras é que há uma heterogeneidade de maneiras de o Estado administrar a vida e que essas práticas e processos estatais nas margens são parte constitutiva dessa ordem, pressupostos necessários do Estado. (DAS; POOLE, 2004).

Em diálogo com essa perspectiva, o argumento deste texto tem como eixo central as explicações dos policiais-professores para os problemas sociais que observavam na favela, explicações fortemente centradas no que eles consideravam ser características inerentes à comunidade. Argumento que as conexões estabelecidas por esses agentes estatais entre as características da comunidade e os problemas ali encontrados eram as bases para justificar e explicar o fracasso e/ou alcance limitado dos projetos. Seriam as próprias características da comunidade refletidas nos indivíduos, nas famílias e na cultura local - que explicariam a manutenção dos problemas sociais e do problema da violência. (MOTTA, 2017). Nesse raciocínio, presente em inúmeras políticas para pobres, oblitera-se uma reflexão sobre a concepção, os desenhos e a implementação da própria política. A ineficácia dos projetos em transformar a realidade emerge como um indicador de quão difícil é a comunidade e seus moradores, fazendo do fracasso a própria prova e justificativa da necessidade e importância da manutenção dessas mesmas políticas.

Para desenvolver tal argumento, o texto se organiza da seguinte maneira. Primeiro, apresento como o contexto das UPP possibilitou que os policiais-professores chegassem aos projetos 
e como eles percebiam o trabalho que realizavam frente à questão da contenção da violência. Em seguida, descrevo e analiso as explicações desses agentes estatais para os problemas da comunidade - que estariam na origem do problema da violência -, as quais agrupei em quatro categorias: 1) a cultura de comunidade; 2) a família desestruturada; 3) a falta de vontade ou comodismo; 4) a ausência do Estado. Na terceira parte, problematizo como essas características atribuídas à comunidade são conectadas às explicações sobre o fracasso e/ou alcance limitado dos projetos, produzindo uma justificativa para a manutenção deles, ancorada na própria ineficácia da política e reforçando a associação entre pobreza e violência.

\section{DE POLICIAIS A POLICIAIS-PROFESSORES: a UPP, os projetos e a cidadania}

Os Centros de Referência da Juventude (CRJ) foram criados pelo governo do Estado do Rio de Janeiro, por volta de 2010, com o objetivo de serem espaços para os jovens de comunidades vulneráveis realizarem atividades por eles propostas ou seguir cursos e atividades propostas por técnicos. A maioria dos CRJ implementados no início da política encontrava-se em comunidades com UPP, como a Cidade de Deus. Entretanto, no caso da Cidade de Deus, a vinculação entre o CRJ e a política de pacificação era ainda mais estreita, pois a maior parte dos cursos oferecidos era ministrada por policiais cedidos pelo comando da UPP local.

No primeiro semestre de 2014, dos nove professores do CRJ, seis eram policiais cedidos pela UPP, os quais ministravam aulas de violão, instrumentos de sopro, inglês, caratê, jiu-jitsu e capoeira, além de um policial fisioterapeuta que fazia atendimentos no local. Em maio de 2016, no segundo momento da pesquisa, dos onze professores, cinco eram policiais, ministrando cursos de caratê, inglês, jiu-jitsu, balé e violão, além do policial fisioterapeuta.

Todos os policiais-professores com os quais estabeleci interlocução estavam na polícia militar há menos de oito anos, ou seja, todos haviam ingressado na corporação após o início da política das Unidades de Polícia Pacificadora, em 2008. Desde seu início, muita coisa aconteceu com a política das UPP: de grande aposta do governo estadual, modelo de política e esperança da população, passou por forte crise, perda de legitimidade e questionamentos sobre sua efetividade até chegar ao esvaziamento completo. ${ }^{4} \mathrm{E}$ foi no seu auge, entre os anos de 2009 e 2011 , que o número de concursos para formação e contratação de policiais atingiu seu pico, acompanhando a expansão acelerada da política das UPP e a premissa de que, para consolidar um novo modelo de policiamento, era preciso renovar a polícia. Não é coincidência, portanto, que todos os policiais com os quais tive contato no CRJ tenham ingressado na polícia nesse momento (entre 2009 e 2012) e tenham sido enviados diretamente ou poucos meses depois de seu ingresso às Unidades de Polícia Pacificadora recém-instaladas. 
O FRACASSO DAS PRÁTICAS ESTATAIS COMO SUA JUSTIFICATIVA: Projetos de Policiais-Professores na Cidade de Deus

O ingresso na polícia em UPP no contexto da implementação das UPPs foi decisivo para que os policiais-professores chegassem aos projetos. Com efeito, a partir de 2009 , mesmo tendo grande respaldo da opinião pública, o governo do Estado do Rio de Janeiro passou a ser questionado sobre os demais serviços públicos, se a chegada do Estado nas comunidades seria apenas por meio da segurança pública. O governo estadual intensificou as ações em áreas pacificadas e promoveu articulações entre políticas municipais, estaduais e federais nesses territórios. Sob o comando das UPP, essas demandas provocaram o aumento de ações, que iam desde a comemoração de aniversários da implantação das Unidades, passando por atividades em datas comemorativas, apoio a ações de outras entidades, mediação de conflitos, chegando à participação em reuniões da comunidade e intervenção em outras políticas. (ARAÚJO; CARVALHO, 2014; CARVALHO, 2014; DAVIS, 2014). ${ }^{5}$

Mas são os projetos de policiais das UPP que ganham destaque nesse esforço de aproximar polícia e comunidade. Apesar de não estarem previstos formalmente, os projetos estavam presentes em todas as UPP. Por não haver uma normativa relativa a eles, não havia critério geral estabelecido sobre os formatos e os tipos de atividades a serem implementadas. Era a combinação entre as competências dos policiais daquela Unidade, a disponibilidade e interesse desses policiais e a avaliação do comandante da UPP local que determinava a implementação de um projeto. ${ }^{6}$ Entretanto, os modos como esses fatores se combinavam eram bastante circunstanciais e dependiam fortemente do comandante, não apenas pela sua avaliação da relevância do projeto, mas também pelo seu perfil, se era um apoiador dos projetos ou não. (MOTTA, 2017).

Assim como acontecia com a escolha dos projetos a serem implementados, faltava um critério e uma diretriz geral também no que se referia à interrupção ou manutenção dos projetos em curso. A cada mudança de comando, os projetos ficavam em uma situação incerta. No entanto, na Cidade de Deus, os projetos dos policiais gozavam de relativa estabilidade, tendo em vista a estrutura física disponível (o Prédio do CRJ), o tempo de existência (alguns existiam desde 2010), o número de alunos, a demanda e o fato de a Cidade de Deus ter se tornado uma vitrine dos projetos sociais das UPP. Por todos esses fatores, mesmo nas trocas de comando, os projetos permaneciam.

Acredito que o fato de estarem há muitos anos nos projetos, terem enfrentado mudanças e o risco de seus projetos serem cancelados e terem colegas policiais compartilhando o mesmo espaço de trabalho permitiu que os policiais-professores da Cidade de Deus construíssem uma reflexão bastante elaborada sobre a especificidade do trabalho que ali realizavam, sobretudo no que se referia às particularidades e distinções entre o trabalho na rua e o projeto. A fala do policial-professor Roberto elucida essa distinção: 


\begin{abstract}
Ou seja, o policial que pode ser um matador, um cara que prende muito na pista, qualquer ser humano pode fazer isso, não estou menosprezando. Estou querendo dizer que, com o treinamento mínimo, você está habilitado para fazer aquilo dali. É um trabalho que ele é mais superficial, é um "enxuga gelo", no caso. Agora, você está como professor da ideologia deles, nem todo mundo pode fazer. Eu conheço muitos policiais colegas meus que falam: "cara, isso daí é o maior tiroteio que tu enfrenta, maior guerra". Porque eu lido com a mente humana, eu não lido com o comportamento só humano. [...] É o que eu faço, é o que os nossos colegas que estão aí, que estão no projeto fazem, a gente lida diretamente com a mente humana. [...] Esse é o nosso trabalho, é um trabalho que é muito complicado. Então quando nós conseguimos diversificar o trabalho da polícia, a polícia consegue fazer esse segundo trabalho, esse segundo emprego de força, porque para mim não deixa de ser um emprego de força [...] Eu agradeço e valorizo muito o choque, o BOPE [Batalhão de Operações Especiais], as pessoas que trabalham na linha de frente, na linha de tiro, porque você está dando o teu corpo de escudo para salvar a nós, que estamos fazendo um segundo trabalho. Mas tão importante quanto o nosso, porque nós estamos numa linha de tiro mental, é um desgaste extremamente emocional e mental para você fazer com que o indivíduo chegue lá fora e não pegue um fuzil para dar tiro num policial que está na linha de tiro; ou seja, eu faço um segundo combate. (Informação verbal) ${ }^{7}$.
\end{abstract}

Para os policiais-professores, a forma de prevenir a violência passava pela guerra, que era feita em frentes distintas, com estratégias específicas. Eles tinham como estratégia central a linha de tiro mental, levada a cabo no cotidiano de cada aula, com cada aluno. Em uma linha de tiro mental, mais importante do que ensinar uma língua, um esporte ou um instrumento era conquistar a mente. Os cursos eram mais uma ponte para chegar aos alunos do que um fim neles mesmos. 0 importante era ocupar os jovens, afastá-los temporal, espacial e mentalmente do tráfico, oferecer a eles outro exemplo; exemplo considerado melhor sob o ponto de vista legal, mas também moral.

De fato, em suas falas sobre esse trabalho de ganhar mentes, fazer um segundo combate, eram recorrentes as expressões levar cidadania, formar cidadãos, transformar em cidadãos. (MOTTA, 2017). A cidadania emerge como categoria central no modo como policiais-professores entendem 0 processo de transformação que almejam operar nas comunidades. Mas o que querem dizer com levar cidadania? O que significa ser cidadão na perspectiva desses policiais-professores? Como o levar cidadania está associado à transformação da comunidade?

Na medida em que a intervenção junto aos pobres é, antes de tudo, uma tentativa de conter e administrar a suposta ameaça que a pobreza conteria (e não garantir direitos), torna-se possível associar o incremento da cidadania a um incremento da ordem, da civilidade e da moral que faltaria a essas populações e que faria delas uma ameaça. A agenda e o tema da segurança invadem e ressignificam a cidadania. A questão essencial, então, é a produção da ordem. Assim, podemos melhor compreender que o modo como os policiais-professores concebiam a cidadania estava estreitamente relacionado à sua principal estratégia para atuar sobre a violência que decorreria das condições de pobreza: a combinação ou complementaridade dos trabalhos de policial e de professor. (MOTTA, 2017). 
A fala de um dos policiais-professores é emblemática da percepção de uma complementaridade entre o trabalho policial e os projetos nesse esforço em formar cidadãos:

\begin{abstract}
Eu aqui, eu ajo como policial sem eles perceberem. Como? Além de ensinar, eu passo pra eles noções de cidadania, de respeito, de obediência. Muitos jovens chegam aqui sem freio, cara, sem limite. E eu converso muito com eles sobre drogas, sobre abordagem (todos sabem que eu sou policial), [...] Eu não chego e falo: "hoje eu vou ensinar vocês a como agirem..." Não! É num bate-papo informal, ou durante a aula, ou antes, da aula ou após a aula. Eu aproveito um gancho, algum comentário, "poxa, não é assim e tal...". Então eu vou incutindo isso neles. [...] Então nisso, eu finjo que sou um professor comum, mas vou mudando eles. Quer dizer, porque muitos têm a visão de que o policial é aquele cara que entra, mata e bate e é ladrão e é isso. Então, aos poucos eu vou modificando. Isso é o que diferencia de um professor comum talvez e não um professor policial. [...] Minha ideia é mais transformar eles. Eu quero pegar aquele jovem que seguiria um caminho errado, que admirava o traficante, odiava o policial, pegar esse cara e botar num caminho bacana, para ele ter uma família, seguir sua profissão, virar uma pessoa de bem, um cidadão de bem. (Informação verbal) $)^{8}$.
\end{abstract}

A ideia, muito recorrente entre os policiais-professores, de que o policial deveria estar sempre presente na sala demonstra que a especificidade do trabalho que realizavam ali não se referia apenas ao fato de serem ações diferentes daquelas que os policiais comumente fazem (patrulha, confrontos etc.), mas reside, sobretudo, no fato de o trabalho social ou de professor ser potencializado e incrementado por sua formação policial. Das contribuições que essa formação policial daria para a atuação nos projetos, um dos principais elementos destacados era a disciplina, que, por sua vez, era muito associada à cidadania. Disciplinar o aluno ou ensiná-lo a ter disciplina nas atividades dos projetos ou na vida era considerado uma forma de incrementar a cidadania, sobretudo porque esse jovem teria mais chances de se manter firme no caminho certo, enfrentado e superando as adversidades.

Mas, para produzir essa transformação, era preciso incidir sobre as características consideradas inerentes às comunidades e aos seus moradores, pois elas seriam a fonte dos problemas encontrados na comunidade $\mathrm{e}$, consequentemente, da violência que delas emanaria. A complementaridade entre a importância das ações sociais dos projetos e o trabalho de repressão na rua ficava evidente: como forma de disciplinar, ordenar, civilizar e reprimir o que é caótico, desorganizado, sem limite e imoral e que, por isso, produziria o crime e a violência. É nessa perspectiva que os policiais-professores frisaram reiteradas vezes que, para conter a violência e o crime, seria preciso pacificar a comunidade. E quais seriam essas características sobre as quais era necessário incidir para pacificar a comunidade e combater a violência?

\title{
3 AS CAUSAS DOS PROBLEMAS DA COMUNIDADE E, CONSEQUENTEMENTE, DA VIOLÊNCIA
}

A maior ou menor possibilidade de entrada no crime era a questão fundamental para os policiais-professores. Nessa lógica, levar cidadania era manter o jovem longe do crime. Entretanto, 
quando a pobreza está associada a perigo e violência e é fortemente atribuída às escolhas e comportamentos dos indivíduos, produzir ordem não se reduz a fazer guerra ao crime ou ao tráfico. É preciso promover uma transformação sobre os modos de vida dessas populações, vistas como potencialmente perigosas. Tudo o que é característico desses territórios e dessas populações é entendido como relacionado ou até mesmo como causa da violência e do crime. Seria preciso intervir sobre as comunidades como um todo, para, assim, produzir uma ordem social supostamente inexistente nesses territórios. (MOTTA, 2017).

Em um esforço de sintetizar e conferir maior clareza às explicações dadas pelos policiaisprofessores e os aspectos associados a elas, apresento o quadro a seguir, que mostra as explicações para os problemas da comunidade agrupadas em quatro categorias:

\section{Quadro 1 - Síntese da origem dos problemas da comunidade, segundo policiais-professores}

\begin{tabular}{|c|c|c|c|}
\hline & Sentidos e conteúdos associados & $\begin{array}{c}\text { Como e porque impacta a } \\
\text { vulnerabilidade (aumenta o risco de ir } \\
\text { para o crime) }\end{array}$ & O que está em disputa \\
\hline Cultura da comunidade & $\begin{array}{l}\text { - Música (funk); } \\
\text { - Expor o corpo (mulheres); } \\
\text { - Sexualidade precoce e banalizada; } \\
\text { - denunciar bante com o tráfico ou não } \\
\text { - Hostilizar policial; } \\
\text { - Falta de visão ou instrução. }\end{array}$ & $\begin{array}{l}\text { - Não conhecer outras realidades; } \\
\text { - Não conseguir se inserir (empregos } \\
\text { melhores, espaços "melhores"); } \\
\text { - Não pensar no futuro; } \\
\text { - O crime trona-se atraente. }\end{array}$ & $\begin{array}{l}\text { - Sexualidade; } \\
\text { - Gosto (música, roupas); } \\
\text { - Imagem e papel da policia; } \\
\text { - O que o crime oferece. }\end{array}$ \\
\hline Família desestruturada & $\begin{array}{l}\text { - Muitos filhos; } \\
\text { - Hulheres engravidam cedo; } \\
\text { filhos; que não assumem os } \\
\text { - Pressão para os filhos trabalharem; } \\
\text { - Condições de moradia precária; } \\
\text { - Não incentivar ou não obrigar } \\
\text { filhos a estudarem ou } \\
\text { permanecerem nos cursos; } \\
\text { - Exemplos negativos (não estudou, } \\
\text { não trabalha, envolvido no crime); } \\
\text { - "Tá no sangue". }\end{array}$ & $\begin{array}{l}\text { - Não estudar; } \\
\text { - Ter trabalho desqualificado/precário } \\
\text { para ajudar em casa; } \\
\text { - Ter condições financeiras ruins; } \\
\text { - Jovem não é estimulado; } \\
\text { - O crime se apresenta como saida } \\
\text { "fácil". }\end{array}$ & $\begin{array}{l}\text { - Modelo de familia; } \\
\text { - Sexualidade; } \\
\text { - Modo de ser mulher; } \\
\text { - Trajetória de vida e de familia; }\end{array}$ \\
\hline $\begin{array}{c}\text { Falta de } \\
\text { vontade/comodismo }\end{array}$ & $\begin{array}{l}\text { - Reproduzir a história da familia } \\
\text { (de pobreza, de dificuldade, de } \\
\text { insucesso, de crime); } \\
\text { - Ser preguiçoso; } \\
\text { - Não arriscar; } \\
\text { - Não aproveitar as oportunidades. }\end{array}$ & $\begin{array}{l}\text { - Não acessar oportunidades; } \\
\text { - Continuar vivendo precariamente; } \\
\text { - Crime aparece como alternativa } \\
\text { "fácil"; }\end{array}$ & $\begin{array}{l}\text { - Forma de pensar o futuro; } \\
\text { - Postura/espirito empreendedor } \\
\text { (correr riscos, superar adversidades, } \\
\text { persistir, ser resiliente); } \\
\text { - Trajetórias alternativas ao crime. }\end{array}$ \\
\hline $\begin{array}{c}\text { Falta ou precariedade da } \\
\text { presença estatal }\end{array}$ & $\begin{array}{l}\text { - Ausência de politicas (não chegam } \\
\text { nas áreas mais pobres); } \\
\text { - Serviços precários (quando chega, } \\
\text { em geral, é ruim). }\end{array}$ & $\begin{array}{l}\text { - Não oferecer oportunidades; } \\
\text { - Aumentar a revolta contra o próprio } \\
\text { estado; } \\
\text { - Deixar mais espaço para o crime; } \\
\text { - Gerar ou aumentar a pobreza. }\end{array}$ & $\begin{array}{l}\text { - Qualidade dos } \text { serviços } \\
\text { comumidades; } \\
\text { - Chegada dos } \\
\text { comunidades. }\end{array}$ \\
\hline
\end{tabular}

Fonte: MOTTA, L. Fazer estado, produzir ordem: sobre projetos e práticas na gestão do conflito urbano em favelas cariocas. 2017. Tese (Doutorado em Sociologia) - Centro de Educação e Ciências Humanas, Universidade Federal de São Carlos, São Carlos, 2017.

A) A cultura da comunidade

Eram $18 \mathrm{~h} 30$ quando Carlos entrou na sala para iniciar a sua aula. Ele começou com as instruções para o aquecimento; todos sabiam o que fazer, eram alunos graduados. Mas uma coisa incomodava Carlos: o som alto na área externa do CRJ. Uma caixa de som muito potente era usada para tocar as músicas de funk dançadas pelos alunos do curso de passinho. Carlos falava cada vez mais alto e, a todo momento, era interrompido por algum aluno que não o escutava e pedia para que ele repetisse a instrução. Era visível que se irritava cada vez mais. Menos de dez minutos após o início 
da aula, ele interrompeu as instruções e se dirigiu à área externa. Pude escutá-lo perguntando quem era 0 responsável pela aula e pedindo que abaixasse 0 volume do som. 0 pedido foi prontamente atendido. Carlos retornou à sala e, ainda irritado, se dirigiu a mim:

\begin{abstract}
Eles falam que isso é aula, que é um curso, mas na verdade eles ficam ouvindo essa música horrivel, de apologia ao crime e ao sexo; as meninas vêm praticamente nuas, com cada short, e ficam dançando. Falam para os pais que vão para um curso no CRJ, mas ficam aí soltos. Nem professor não tem, o responsável é um moleque mesmo, como todos, não tem formação nem nada (Informação verbal) ${ }^{9}$.
\end{abstract}

Eu disse que era uma situação difícil, mas que o importante era que ele conseguisse dar a sua aula. A aula continuou, com o som um pouco mais baixo, mas com Carlos ainda incomodado. 0 funk era um dos principais alvos das críticas que os policiais-professores faziam ao que chamavam de cultura de favela ou de comunidade. Esse estilo musical representaria e condensaria diversos elementos característicos de comunidade avaliados como negativos, danosos, problemáticos e até perigosos. 0 ritmo, as letras e os eventos característicos do funk seriam uma exaltação e um incentivo para que mulheres se vestissem de determinados modos (roupas curtas e decotadas), à banalização de relações sexuais, à apologia ao tráfico e aos traficantes, à rejeição à polícia.

Um dos principais elementos atribuídos à cultura da comunidade e relacionado ao funk $\mathrm{e}$ aos bailes funk era o comportamento de meninas e mulheres com relação ao seu corpo e sua sexualidade. As falas dos policiais-professores deixavam explícita a conexão estabelecida entre 0 modo como as mulheres figuram nas letras de funk e determinados comportamentos comuns entre meninas e mulheres de comunidade. É interessante notar como essa percepção era conectada, de modo causal, ao que seriam outras duas características de comunidades: a banalização das relações sexuais, que teria como consequência a gravidez precoce, e o número elevado de filhos por mulher. Esses elementos, por sua vez, estariam diretamente relacionados à desestrutura familiar.

Essas críticas que relacionavam o funk a um comportamento inadequado das mulheres de comunidades eram explícitas nas aulas de balé. $O$ balé era considerado pelos policiais-professores não apenas como uma atividade que ocupava as meninas (em todas as turmas, havia apenas um menino), mas apresentava a elas um estilo alternativo ao funk, oferecia a elas a oportunidade de aprender comportamentos e posturas femininos e delicados.

Aqui, é interessante destacar como a cidadania almejada coincide com o gosto por determinadas músicas e danças, coincide com uma forma de expor e usar o corpo, é sinônimo de um estilo de vida que, mesmo não sendo explicitado, precisa ser diferente daquele relacionado à cultura da comunidade. Portanto, para formar um cidadão, é preciso ensinar outros gostos, outras posturas, outro jeito de ser mulher - e quanto mais cedo melhor. Também fica evidente que essa preocupação e essa disputa pelo corpo se dão com maior intensidade quando se trata de mulheres. Os homens de 
comunidade são mencionados como tendo a cultura de não assumirem seus filhos, portanto cabe às mulheres, sabendo disso, se darem ao respeito.

Mas a reprovação ao fato de muitas mulheres gostarem de funk, dançarem e frequentarem bailes não se restringia ao modo como se vestiam e como vivenciavam sua sexualidade. Os policiais-professores também associavam o gosto das mulheres pelo funk e pelo que ele exalta à atração e ao interesse que elas, sobretudo aquelas mais jovens, teriam por homens envolvidos em atividades criminosas e pelo status de estarem vinculadas a essas atividades. Usar roupas curtas e decotadas, ir a bailes funk, dançar e escutar funk seria um indicativo de que essas mulheres estariam interessadas pelos supostos benefícios que a vida do crime poderia trazer, como dinheiro, poder e status.

Com efeito, a comparação e a tensão estabelecida entre, de um lado, as aulas de artes marciais e balé e, de outro, as aulas de passinho, deixava entrever uma oposição entre ordem e desordem. O que era característico da comunidade - música, dança, formas de vestir e viver a sexualidade, modos de lazer - era associado à desordem, ao imoral e, consequentemente, ao crime, ao ilegal. Portanto, para os policiais-professores, para impedir ou diminuir o impacto da cultura da comunidade sobre seus problemas, era preciso mostrar para os jovens como a sua forma de lidar com o corpo e com a sexualidade era equivocada, degradante, danosa. Era importante mostrar que apreciar o funk era não apenas degradar a mulher e incitar a sexualidade precoce, mas também, e mais grave, era exaltar o crime e apoiar o lado errado.

\section{B) A família desestruturada}

As falas dos policiais-professores sobre os efeitos da desestrutura familiar estavam estreitamente relacionadas àquelas sobre a cultura da comunidade. No entendimento deles, a cultura da comunidade englobava as dinâmicas e a organização familiar, informando a maneira como as pessoas do lugar viam as relações entre familiares, o que, por sua vez e em um movimento cíclico, alimentaria e reforçaria a cultura da comunidade. Talvez o exemplo mais evidente sejam as críticas que faziam à forma como as jovens e as mulheres viviam sua sexualidade. Na perspectiva dos policiaisprofessores, esse comportamento fazia com que elas banalizassem as relações sexuais, iniciando a vida sexual muito jovens. $E$ isso era estreitamente vinculado às críticas que faziam ao número elevado de filhos que as mulheres costumavam ter.

De fato, a família figurava como um elemento central nas explicações sobre os problemas da comunidade. Os pais, mas principalmente as mães, apareceram nas falas dos policiais-professores como sujeitos centrais, decisivos e, muitas vezes, responsáveis pelas trajetórias dos jovens, 
especialmente aquelas trajetórias de fracasso. Para esses agentes, a família desestruturada possuía, predominantemente, dois perfis: i) famílias com muitos filhos e/ou pais ausentes, que não incentivavam os filhos a seguirem um sonho ou a praticar as atividades disponíveis nos projetos; e ii) famílias com um ou mais membros envolvidos em atividades ligadas ao crime. Os policiais-professores afirmavam que a falta de apoio dos pais para que os jovens, sobretudo aqueles considerados com potencial, seguissem treinando, era uma forma de desestimular o jovem, que tendia a desistir dos cursos. Essa desistência significava, na percepção deles, que os jovens teriam mais tempo ocioso, passariam mais tempo na rua e, assim, estariam mais próximos e suscetíveis ao crime. Mas a família era mais fortemente responsabilizada se estava associada a atividades ligadas ao crime. Essa responsabilização se referia a casos de famílias com vários membros, há várias gerações, engajados nessas atividades, mas também àquelas em que o pai, um irmão ou um parente próximo estava envolvido com o crime.

A família desestruturada e problemática era associada também às condições materiais (residir em moradia precária, ter renda familiar muito baixa), às características dos pais (muito ausentes, que não apoiavam os filhos, não davam exemplos aos filhos, muito rígidos ou autoritários, sem formação ou informação) e às relações familiares (pais ou parentes violentos, parentes envolvidos com atividades ligadas ao crime). Todos esses elementos, isolados ou articulados, constituíam o que denominavam família desestruturada. Nessa perspectiva, a plasticidade da categoria família desestruturada fica evidente.

\section{C) A falta de vontade}

Em geral, a falta de vontade ou o comodismo eram motivo de alerta por poderem levar o jovem a se envolver com o crime, na medida em que ele oferecia uma saída aparentemente menos trabalhosa e mais imediata. Não havia um questionamento sobre o modo como os projetos aconteciam, se 0 formato agradava aos jovens ou o que poderia ser feito para atrair os jovens. Um professor-policial me explicou sobre a evasão de sua turma:

Na verdade, $97 \%$ não chegam a completar os três anos [de curso], tem uns $3 \%$ aí que chega. Esses 3\% que chegam estão na faixa etária de 30 a 40 anos, ou de 25 a 40 anos. São aquelas pessoas que sabem a importância do curso. [...] 0 adolescente, ele [...] não leva muito a sério, ele entra aqui e brinca, ele conversa; então chega na prova, ele toma porrada. Aí volta e, nisso, sai. Então, o perfil que eu tenho dos alunos que chegam são de 25 a 40 anos, é aquele pessoal que quer realmente aprender, sabe a importância, é um pessoal que trabalha, corre atrás, se esforça mesmo. [...] As minhas turmas de manhã é que têm a evasão maior, porque eles ficam com preguiça de acordar. Eu tenho turma que começa 10 h30 da manhã; eu encontro aluno ali fora "pô, você parou por quê?", "ah, professor, pra chegar lá 10 h30 fica difícil” (Informação verbal) ${ }^{10}$. 
As falas dos policiais-professores sobre a falta de vontade ou comodismo estavam claramente ancoradas no discurso que exalta o empreendedorismo. Eram perpassadas pelo pressuposto de que cada indivíduo escolhe o seu destino, decide ou não superar as adversidades (pobreza, família desestruturada, falta de oportunidade, acesso a políticas etc.). Quando mobilizavam essa explicação, colocavam o indivíduo no centro dos problemas e também das soluções para a situação de vulnerabilidade. O comodismo, a preguiça ou a falta de vontade faria com que esses jovens permanecessem na comunidade e reproduzissem a condição de pobreza, de falta de oportunidades, o que, por sua vez, faria com que estivessem mais propensos a ver saídas mais fáceis no crime.

D) A falta de Estado

\begin{abstract}
Quando o governo joga um policial militar dentro da comunidade. 0 certo seria que ele não jogasse só o policial militar dentro de uma comunidade, porque para se pacificar, tem que ter todo um conjunto; para eu pacificar um cidadão da comunidade, eu tenho que dar para ele um bom saneamento básico, eu tenho que dar para ele uma boa prestação de serviço na questão médica, eu tenho que dar para ele uma boa prestação de serviço na questão da educação. [...] O que é o Estado? A polícia militar... nós, policiais militares, a gente representa o estado do Rio de Janeiro. Como é que você vai respeitar um policial militar se dentro da sua casa corre um esgoto? Como é que você vai respeitar um policial militar se dentro da sua comunidade sua mãe morreu na fila de espera do UPA [Unidade de Pronto Atendimento]? Como é que você vai me respeitar, policial militar, se você colocou a sua filha de dois anos na escola e ela está analfabeta até hoje? Então, realmente, o cidadão na comunidade, ele fica arredio, ele fica violento, ele fica com raiva. Então, como ele não tem para quem brigar, ele vai brigar com quem? 0 policial militar, que é a parte mais próxima do Estado. Então, não é culpa nem da comunidade e nem do policial militar; para mim é culpa do Estado, que está fazendo um projeto que nem ele mesmo conseguiu fazer (Informação verbal) ${ }^{11}$.
\end{abstract}

A expressão jogado na comunidade deixa evidente o sentimento dos policiais de que estão isolados e desamparados. Mas também deixa entrever como o Estado se apresenta como um outro, que não valoriza ou reconhece - e, por isso, joga - exatamente aqueles que reivindicam ser o seu braço armado. A expressão também denota a brutalidade que sentem por estarem na ponta como policial em comunidade, tendo em vista as dificuldades e os riscos enfrentados. Na fala do policialprofessor, a dimensão colocada em relevo, nessa crítica ao Estado, é a mesma feita por seus colegas: a política de pacificação é muito limitada, porque não adianta chegar só com segurança - que é importante, mas não suficiente. Também fica evidente que, além da insuficiência de focar apenas na 
O FRACASSO DAS PRÁTICAS ESTATAIS COMO SUA JUSTIFICATIVA: Projetos de Policiais-Professores na Cidade de Deus

segurança, a ausência de outras políticas produz uma série de problemas, deficiências, hostilidades e rejeições que a polícia não pode controlar, mas com as quais tem que lidar.

Quando os policiais-professores falavam da falta de Estado, o foco da explicação dos problemas mudava consideravelmente; a dimensão da responsabilização do sujeito, da família e da comunidade desaparecia. As ações de rejeição à polícia eram atribuídas ao Estado, ou melhor, à falta e à qualidade ruim das políticas públicas, que deixavam os moradores de comunidade sem acesso a serviços básicos. Até o traficante deixava de ser visto como um agente que causava problemas e desestruturava a comunidade, na medida em que suas ações eram explicadas como decorrentes da precariedade da ação do Estado.

É importante problematizar, ainda que brevemente, a ideia bastante difundida de ausência de Estado, pois, com efeito, o que podemos observar em favelas e periferias é uma intensa presença de agentes estatais no seu cotidiano. Assistentes sociais, técnicos sociais, policiais, profissionais da saúde, de serviços epidemiológicos, profissionais da área da cultura, além de escolas, unidades de saúde, serviços de coleta seletiva, iluminação e abastecimento de água são alguns exemplos disso. Entretanto, a presença de toda essa diversidade de agentes estatais de vários campos da gestão pública não se traduz em melhorias nas condições de vida locais nem em transformações estruturais. Por isso, comumente fala-se de ausência de Estado, quando a expressão mais apropriada seria uma ausência de eficiência e efetividade da presença estatal nesses territórios.

O que deve ser destacado para a discussão que aqui se desenvolve é que as explicações que poderíamos considerar como sendo de ordem estrutural (a ausência ou baixa qualidade de serviços públicos em áreas mais pobres ou mais vulneráveis, segundo os termos dos policiaisprofessores) existiam juntas e simultaneamente com explicações que culpabilizavam e responsabilizavam os sujeitos, que preconizavam que eles deveriam se superar, arriscar e empreender, no sentido de serem empreendedores de si mesmos. (FOUCAULT, 2008; BOLTANSKI; CHIAPELLO, 2009). Todavia, apesar de essas duas explicações estarem presentes nas falas dos policiaisprofessores, em última instância e nas situações concretas, as explicações individualizantes se sobrepunham aos aspectos estruturais. As falas admitiam que havia precariedade, mas sempre destacavam que o jovem não podia se abater diante das dificuldades que a vida the apresentava. A falta de políticas era reposicionada, no limite, de modo a se tornar algo que podia ser sempre superado, subsumindo a dimensão das desigualdades, da estigmatização, da falta de serviços e de oportunidades. No limite, era o indivíduo com sua falta de vontade, a família com sua desestrutura e, no máximo, a comunidade com sua cultura os responsáveis pelos problemas vivenciados. (MOTTA, 2017). 
O importante a reter é que, à medida que a dimensão estrutural é ocultada pelas explicações focadas nos sujeitos e suas escolhas, é produzida e reproduzida uma lógica que responsabiliza as comunidades, com suas famílias e indivíduos, pelos seus problemas. Assim, torna-se possível atribuir o problema da violência a certos territórios e indivíduos, vinculando-o à pobreza. Nessa esteira, o alcance limitado ou o fracasso dos projetos também passa a ser explicado por essas características da comunidade. Seriam a desordenada cultura da comunidade, próxima ao crime e hiper sexualizada, as famílias desestruturadas, os indivíduos que não têm vontade e se acomodam que, ao produzirem um cenário de desordem e falta de limite extremos, explicariam a falta de efetividade dos projetos.

\section{DA EXPLICAÇÃO PARA O FRACASSO AO FRACASSO COMO JUSTIFICATIVA PARA OS PROJETOS}

Lembro-me de ter ouvido, com surpresa, as cifras apresentadas pelo policial-professor: menos de $10 \%$ dos alunos completavam seu curso; achei muito pouco. Essa fala, já no fim da segunda fase do trabalho de campo, me fez retomar um questionamento que me fiz por várias vezes ao longo da pesquisa e das leituras do caderno de campo: por que os policiais-professores se mantinham tão engajados? Perguntava-me, exatamente, sobre o engajamento e não sobre o porquê de continuarem trabalhando ali. Se o ponto fosse esse, poderia ser explicado por questões de ordem objetiva, como manutenção do emprego, menos perigo do que estar na rua, proximidade com o local de residência. Eu presenciava 0 aumento de confrontos armados entre policiais e traficantes, acompanhava a alta rotatividade dos alunos nos cursos, ouvia os relatos das dificuldades de fazer com que os jovens fossem aos cursos. De fato, esses agentes pareciam não se abalar com as sucessivas e inúmeras provas, indícios e sinais de que a transformação não estava ocorrendo: os jovens não estavam tendo mais oportunidades, as famílias não estavam mais estruturadas, o crime não estava enfraquecido, a cultura da comunidade continuava a mesma. Perguntava-me, cada vez mais: por que não desistiam e deixavam de acreditar que o que faziam produzia resultados? Intrigava-me essa espécie de resiliência frente à manutenção do que procuravam transformar e ordenar.

\footnotetext{
A gente não está aqui pra mudar o mundo, a gente não tá viajando na maionese, a gente sabe a realidade, a gente sabe que a gente não vai conseguir resolver o problema, a gente não vai acabar com as drogas, a gente não vai acabar com o tráfico nem com armas, mas a gente vai ajudar alguém, com certeza, eu tenho certeza alguém vai ser ajudado, mesmo que seja uma pessoa só, pra mim tá valendo a pena (Informação verbal) ${ }^{12}$.
}

Um dos pontos centrais da fala desse policial-professor - recorrente nas falas de seus colegas - era a consciência dos limites e limitações que deixavam o trabalho abaixo do que deveria ser, que contrastava com o engajamento deles em responderem a essas demandas, o que implicava 
O FRACASSO DAS PRÁTICAS ESTATAIS COMO SUA JUSTIFICATIVA: Projetos de Policiais-Professores na Cidade de Deus

um compromisso com o trabalho, com uma causa, presente no trabalho que realizavam. Isso fazia com que parecessem impermeáveis ao fato de que a realidade da Cidade de Deus não se alterava - ou, na melhor das hipóteses, melhorava muito pouco; na pior, piorava.

É importante frisar que, se as transformações estruturais não ocorriam, a participação de crianças e jovens nos projetos era uma oportunidade que podia, de fato, abrir muitas possibilidades de acesso, experiências e ampliação de horizontes. Muitos viajaram para competições em outras cidades ou estados, o que nunca tinham feito ou fariam sozinhos. Conheci histórias de alunos que começaram aulas de violão e encontraram nessa atividade uma forma de sustento. Conversei com mães que me relataram que seus filhos passaram a ter melhor rendimento na escola depois que iniciaram a prática de artes marciais. Conheci um casal de irmãos de 6 e 9 anos que descobriram nas aulas de flauta uma paixão. Portanto, dizer que os projetos não tiveram êxito não é dizer que indivíduos não se beneficiaram deles; é frisar, como os policiais-professores, que as dinâmicas mais gerais continuavam intactas.

É evidente que essas vitórias individuais faziam com que os policiais-professores se alegrassem e sentissem satisfação pelo trabalho que realizavam. Mas não se tratava de uma espécie de alienação, como uma explicação apressada e superficial poderia sugerir. Eles mesmos me diziam que conheciam aquela realidade, me explicavam como e o que conheciam. Era óbvio que viam e sentiam tudo que não dava certo, a transformação que não vinha e, possivelmente, não viria. De fato, o que se passava ali parecia ser mais um processo de tornar plausível o mundo, um esforço de conferir valor ao trabalho que faziam, dar sentido ao envolvimento que tinham - sobretudo para eles mesmos. Nessa leitura otimista, paradoxalmente, o fracasso emergia como sinal de que o trabalho era ainda mais necessário.

Apesar de reconhecerem que a instabilidade, as cobranças, a falta de apoio, recursos e infraestrutura contribuíam para que os projetos não fossem tão efetivos, os policiais-professores acreditavam que eram as características da comunidade - sobre as quais deveriam incidir para transformar - as causas para o alcance limitado dos projetos. Com efeito, não eram problematizadas as concepções que orientavam a política das UPP e os projetos, assim como não eram questionados o desenho, o planejamento e as estratégias de implementação dessas ações. A relação entre comunidade e polícia era problemática porque na cultura da comunidade havia uma rejeição à polícia e uma preferência pelo tráfico. Os jovens evadiam dos projetos porque suas famílias eram desestruturadas ou porque eram acomodados e imediatistas. Nessa perspectiva, não havia conexão entre a evasão e a história das práticas da polícia em favelas ou mesmo entre as linguagens e as práticas rotineiras dos policiais-professores nos projetos. Ou seja, esses agentes estatais não consideravam que o fato de estarem muito abaixo das metas, expectativas e objetivos era um sinal de 
fracasso do trabalho. Não cogitam questionar o próprio formato dos projetos - no sentido dos perfis, dos comportamentos que esperavam, dos julgamentos que faziam sobre formas de vestir, de falar, da estrutura da família, dos custos eventuais etc. Ao contrário, para eles, o fato de os projetos não terem o êxito esperado sinalizava, de modo paradoxal, que havia a necessidade de continuarem.

Mesmo depois de tanto tempo, de tanta prática, os projetos continuavam a não funcionar. A pobreza continuava, o crime também; os jovens continuavam sem acessar políticas, com empregos precários. E, mais importante, tudo isso continuaria a gerar violência, afinal a favela continua violenta e a cidade também. Assim, havia uma busca incessante por recapturar o que insistia em escapar, capturar o que ainda estava fora, governar o ingovernável. A dificuldade de fazê-lo seria a prova da gravidade da desordem, da imoralidade, do caos. (MOTTA, 2017).

Mesmo construindo explicações, se apoiando em lógicas que responsabilizavam os indivíduos, se apegando às pequenas conquistas, enfim, mesmo tornando o fracasso do trabalho que fazem algo plausível, policiais-professores sofriam. Frustração talvez seja a palavra que descreva um sentimento recorrente desses agentes na ponta, além de ser uma palavra muito usada por eles. Mas eles continuavam, persistiam, não desistiam frente às adversidades, dificuldades e frustrações - atraso de salários, acordos não cumpridos, falta de infraestrutura, piora no quadro dos confrontos na CDD, fracasso das UPP, falência do Estado do Rio de Janeiro. E é essa resiliência que deixava entrever que os capilarizados discursos - permeados pelas ideias de superação, força de vontade, empreendedorismo e responsabilização individual - não estavam a constituir apenas os sujeitos atendidos, mas também aqueles que os atendiam. É nesse sentido que esses agentes na ponta eram parte de um esforço em produzir novos sujeitos e subjetividades - mais ordenados, moralizados, disciplinados, certos -, mas o discurso de superação também os constituía como sujeitos; eles se tornavam, frente a todas as dificuldades, exemplos desse próprio discurso.

Dessa forma, esses agentes na ponta não apenas faziam Estado em suas práticas cotidianas, mas estavam sendo feitos, também pelo que se anuncia como estatal, no exercício do seu trabalho cotidiano junto a populações consideradas e denominadas vulneráveis. Se suas práticas produziam efeitos sobre os jovens que atendiam, reproduziam discursos e formas de gestão (FOUCAULT, 2008), elas também eram efeitos de representações sobre os pobres como perigo e ameaça. Representação na qual suas próprias práticas de persistência figuravam como 0 contraexemplo e, nessa medida, justificavam a ideia de que a pobreza se relaciona com crime e violência por simples escolha individual. 
O FRACASSO DAS PRÁTICAS ESTATAIS COMO SUA JUSTIFICATIVA: Projetos de Policiais-Professores na Cidade de Deus

\section{CONCLUSÃO}

Como procurei mostrar com as falas dos policiais-professores, os agentes estatais que estão na ponta da implementação de uma política operam no cotidiano a partir de um pressuposto que converge com a figuração do conflito urbano contemporâneo: a questão da pobreza é uma ameaça em potencial de violência à sociedade; logo, é uma questão de segurança pública. Dessa perspectiva, é possível compreender que as práticas desses agentes nas margens do Estado (DAS; POOLE, 2004) não são falhas. Elas são o resultado de uma confluência de processos, lógicas e julgamentos morais que constituem o Estado e não uma disfunção de seu funcionamento.

Nessa empreitada para conter o conflito urbano violento, a grande aposta dos policiaisprofessores era combinar ações sociais - como os projetos - e de repressão. Para tanto, era preciso identificar as características da comunidade e, então, transformá-las para impedir que a pobreza se tornasse crime e violência. Era preciso ganhar mentes e corpos, mudando a cultura da comunidade, a família desestruturada, a falta de vontade individual e a falta de Estado. Todavia, se a transformação social não vinha, se os projetos se esvaziavam, se a questão da violência continuava ou piorava, onde estaria o problema? Para os policiais-professores, a falta de efetividade de suas ações era um indicativo da gravidade e profundidade das características da comunidade, que insistiam em persistir. Para eles, não havia nenhuma ligação com o desenho das políticas, com a histórica relação entre polícia e comunidades ou com os modos como essas ações eram implementadas. $O$ fracasso dos projetos passa a funcionar como um indicativo e uma justificativa para a manutenção e continuidade dos projetos. Parece-me que esse raciocínio perpassa uma diversidade de políticas junto a populações e territórios de pobreza, na medida em que se consolidou um discurso de responsabilização individual.

Tal raciocínio é possível tanto pela vinculação direta e automática entre pobreza e violência como pelo apagamento das dimensões estruturais da pobreza e da desigualdade. A convergência entre esses dois discursos hegemônicos sobre a pobreza permite que as ideias de universalização de direitos, garantia de acesso a serviços públicos e condições de vida digna também desapareçam do debate, uma vez que o centro e o responsável por sua situação é o próprio indivíduo, com sua família desestruturada e sua cultura. Não há uma problematização acerca do fato de as estratégias, pressupostos e formas de intervenção se pautarem em discursos individualizantes e de gestão. Nem se considera a possibilidade de serem diferentes.

Desse modo, toda essa atuação social passa a ser, fundamentalmente, uma questão de segurança pública. Essa invasão do social pela segurança opera como uma resposta às demandas por soluções para o conflito urbano contemporâneo, no qual a questão da pobreza se torna, cada vez mais, como já dito, uma questão de violência e, consequentemente, de segurança pública e de polícia. Tal 
invasão responde às demandas por repressão, isolamento e reforça as próprias demandas, na medida em que opera a partir dessa mesma lógica, conferindo materialidade a ela.

Nessa lógica, os projetos dos policiais-professores na Cidade de Deus faziam todo sentido, porque se tratava não de menos segurança, mas de outras formas de fazer e produzir segurança, o que significava maior possibilidade de controle, de disciplina, de produção de ordem e de sujeitos. (FOUCAULT, 2000).

\section{REFERÊNCIAS}

ARAÚJO, M.; CARVALHO, M. Circuitos políticos em uma favela pacificada: os desafios da mediação. Dilemas: Revista de Estudos de Conflito e Controle Social, Rio de Janeiro, v. 8, n. 1, p. 63-76, 2014.

BOLTANSKI, B.; CHIAPELLO, È. O novo espírito do capitalismo. São Paulo: Editora WMF Martins Fontes, 2009.

CANO, I.; BORGES, D.; RIBEIRO, E. Os donos do morro: uma análise exploratória do impacto das Unidades de Polícia Pacificadora no Rio de Janeiro. São Paulo: Fórum Brasileiro de Segurança Pública, 2012.

CARVALHO, M. Os dilemas da "pacificação": práticas de controle e disciplinarização na "gestão da paz" em uma favela no Rio de Janeiro. 2014. Tese (Doutorado em Ciências Sociais) - Universidade Estadual do Rio de Janeiro, Rio de Janeiro, 2014.

DAS, V.; POOLE, D. (eds.). Anthropology in the margins of the state. Santa Fé: School of American Research Press, 2004.

DAVIS, F. A. Rituais de "pacificação": uma análise das reuniões organizadas pelos comandos das UPPs. Revista Brasileira de Segurança Pública, São Paulo, v. 8, n. 1, p. 24-46, 2014.

FASSIN, D. et al. Juger, réprimer, accompagner: essai sur la morale de l'état. Paris: Seuil, 2013.

FELTRAN, G. S. Crime e periferia. In RATON, J.; LIMA, R.; AZEVEDO, R. Crime, polícia e justiça no Brasil. São Paulo: Editora Contexto/ Fórum Brasileiro de Segurança Pública, 2014a.

FELTRAN, G. S. Fronteiras de tensão. São Paulo: Editora da UNESP; CEM; CEBRAP, 2011.

FELTRAN, G. S. O valor dos pobres: a aposta no dinheiro como mediação para o conflito social contemporâneo. Cadernos CRH, Salvador, v. 27, n. 72, p. 495-512, 2014b.

FOUCAULT, M. Microfísica do Poder. Rio de Janeiro: Edições Graal, 2000.

FOUCAULT, M. Segurança, território e população: curso no Collège de France (1977-1978). São Paulo: Martins Fontes, 2008.

FRIDMAN, L. C. Delegação de poder discricionário: o sonho de paz. Dilemas: Revista de Estudos de Conflito e Controle Social, Rio de Janeiro, v. 7, n. 4, p. 611-622, 2014. 
LEITE, M. Da "metáfora da guerra" ao projeto de "pacificação": favelas e políticas de segurança pública no Rio de Janeiro. Revista de Segurança Pública, São Paulo, v. 6, n. 2, p. 374-389, 2012.

LIPSKY, M. Street-level bureaucracy: dilemas of individual in public services. New York: Russel Sage Foundation, 1980.

MACHADO DA SILVA, L. A Violência urbana, segurança pública e favelas - o caso do Rio de Janeiro atual. Caderno CRH, Salvador, v. 23, n. 59, p. 283-300, 2010.

MACHADO DA SILVA, L. Polícia e violência urbana em uma cidade brasileira. Etnográfica, Lisboa, v. 15, n. 1, p. 67-82, 2011.

MACHADO DA SILVA, L.; LEITE, M. S. P. Apresentação de dossiê: continuidades e mudanças em favelas "pacificadas". Dilemas: Revista de Estudos de Conflito e Controle Social, Rio de Janeiro, v. 7, n. 4, p. 607-611, 2014.

MACHADO, C. A igreja ajuda a UPP e a UPP ajuda a igreja: reflexões sobre pacificação, religião e política a partir de uma igreja Assembleia de Deus da Baixada Fluminense. In: ENCONTRO ANUAL DA ANPOCS, 37., Águas de Lindóia, SP, 2013. Anais... Águas de Lindóia, SP: ANPOCS, 2013.

MENEZES, P. Entre o fogo cruzado e o campo minado: uma etnografia do processo de pacificação de favelas cariocas. 2015. Tese (Doutorado em Sociologia) - Instituto de Estudos Sociais e Políticos, Universidade do Estado do Rio de Janeiro, Rio de Janeiro, 2015.

MISSE, M. Crime e pobreza: velhos enfoques, novos problemas. In SEMINÁRIO BRASIL EM PERSPECTIVA: os anos 1990, 1993, Rio de Janeiro. Anais... Rio de Janeiro: Laboratório de Pesquisa Social/IFCS-UFRJ, 1993.

MITCHELL, T. Society, economy and the state effect. In STEINMETZ. G. (org.). State/Culture: stateformation after the cultural turn. New York: Cornell University Press, 1999. p. 76-97.

MOTTA, L. Fazer estado, produzir ordem: sobre projetos e práticas na gestão do conflito urbano em favelas cariocas. 2017. Tese (Doutorado em Sociologia) - Centro de Educação e Ciências Humanas, Universidade Federal de São Carlos, São Carlos, 2017.

PACHECO DE OLIVEIRA, J. Pacificação e tutela militar na gestão de populações e territórios. Mana, Rio de Janeiro, v. 20, n. 1, p. 125-161, 2014.

ROCHA, L. M.; PALERMO, L. C. "O Morro está na calmaria”: mídia impressa e o repertório da paz no contexto da "pacificação". Dilemas: Revista de Estudos de Conflito e Controle Social, Rio de Janeiro, v. 8, n. 1, p. 25-40, 2015.

RODRIGUES, A.; SIQUEIRA, R.; LISSOVSKY, M. Unidades de Polícia Pacificadora: debates e reflexões. Comunicações do ISER, Rio de Janeiro, n. 67, ano 31, 2012.

SOUZA LIMA, A. C. Sobre gestar e gerir a desigualdade: pontos de investigação e diálogo. In: SOUZA LIMA, A. C. (org.). Gestar e gerir: estudos para uma Antropologia da administração pública no Brasil. Rio de Janeiro: Relume-Dumará, 2002. 


\section{Notas}

1 Registro que este texto tem por base os resultados de pesquisa abordados na tese de doutorado (MOTTA, 2017) defendida junto ao Programa de Pós-Graduação em Sociologia da Universidade Federal de São Carlos. A pesquisa contou com financiamento da Fundação de Amparo à Pesquisa do Estado de São Paulo, modalidade Bolsa de Doutorado Regular. Processo 2013/22620-6.

2 Utilizo o termo projetos em itálico por ser o modo como os policiais-professores se referiam ao seu trabalho. Vale lembrar que o termo remete a projetos sociais, muito comuns em favelas e periferias.

3 Utilizo o termo policial-professor para me referir aos policiais que ministravam aulas no âmbito do Programa do CRJ porque, em suas falas, eles sempre frisavam que o policial sempre estava presente em sala de aula; apesar de serem professores, eles eram, antes de tudo, policiais. Por isso a utilização do termo policial antes do termo professor.

4 Para uma reconstrução de todo o processo de constituição da política de segurança das UPP, ver o trabalho de Menezes (2015). Ainda sobre as UPP, ver Leite (2012), Machado (2013), Machado da Silva e Leite (2014), Fridman (2014), Pacheco de Oliveira (2014) e Rocha e Palermo (2015). Para diagnósticos e avaliações sobre o projeto, ver Rodrigues, Siqueira e Lissovsky (2012) e Cano, Borges e Ribeiro (2012).

$5 \mathrm{Na}$ internet, há diversos vídeos sobre os projetos sociais desenvolvidos por policiais (Disponivel em: https:// www.youtube.com/watch?v=_WaTmL1pB7k; https://www.youtube.com/watch?v=PSFInpC8aaU). Na página da UPP, há diversas notícias sobre os projetos (Disponível em: http://www.upprj.com/).

${ }^{6}$ Predominam nos projetos de policiais das UPP os cursos de artes marciais em geral, aulas de instrumentos musicais (violão e cavaquinho), escolinhas de futebol, aulas de dança e reforço escolar.

7 Depoimento de Roberto, policial-professor no CRJ, junho de 2016.

8 Depoimento de Jaime, policial-professor no CRJ, abril de 2016.

9 Depoimento de Carlos, policial-professor do CRJ, abril de 2016.

10 Depoimento de Cleber, policial-professor no CRJ, abril de 2016.

11 Depoimento de Vinícius, policial-professor no CRJ, junho de 2016.

12 Depoimento de Antônio, policial-professor no CRJ, junho de 2016. 